\title{
Preoperative renal dysfunction does not affect outcomes of left ventricular assist device implantation
}

\author{
Arman Kilic, MD, ${ }^{\mathrm{a}}$ Carol W. Chen, MD, ${ }^{\mathrm{b}}$ Ann C. Gaffey, MD, ${ }^{\mathrm{b}}$ Joyce W. Wald, DO, \\ Michael A. Acker, MD, and Pavan Atluri, MD $^{\mathrm{b}}$
}

\section{ABSTRACT}

Objective: Selection criteria for durable left ventricular assist device (LVAD) implantation remain unclear. One such criterion is renal function. In this study we evaluated outcomes of LVAD implantation in patients with preoperative renal dysfunction.

Methods: Patients with implanted LVADs as destination therapy (DT) or bridge to transplantation (BTT) at a single institution between 2006 and 2015 were included. Primary stratification was according to pre-implantation glomerular filtration rate (GFR): $>60 \mathrm{~mL} / \mathrm{min}$ versus $<60 \mathrm{~mL} / \mathrm{min}$ or dialysis dependence. The primary outcome was post-LVAD implantation overall survival.

Results: Two hundred thirty-eight patients underwent LVAD implantation during the study period as DT $(60 \% ; n=142)$ or BTT $(40 \% ; n=96)$. Reduced GFR was present in $56 \%(\mathrm{n}=132)$, with $8 \%(\mathrm{n}=18)$ being dialysis-dependent. Normal versus reduced GFR cohorts were well matched except for a higher incidence of coronary artery disease in the patients with reduced GFR $(61 \%$ vs $48 \%$; $P=.04)$. Mean follow-up was $13.5 \pm 17.0$ months. Unadjusted and riskadjusted survival at 1, 3, 6, and 12 months after LVAD implantation were similar between the cohorts for DT and BTT. Rates of transplantation were comparable in BTT patients $(61 \%$ normal vs $53 \%$ reduced GFR; $P=.43)$. Recovery of renal function to a GFR $>60 \mathrm{~mL} / \mathrm{min}$ occurred in $43 \%(\mathrm{n}=17)$ and $57 \%(\mathrm{n}=42)$ of patients with reduced GFR in the BTT and DT cohorts, respectively, by 1 year post implantation.

Conclusions: Well selected patients with preexisting renal dysfunction can undergo LVAD implantation with acceptable outcomes. Approximately half of LVAD recipients with preimplantation renal dysfunction will recover normal renal function within the first postoperative year. Renal dysfunction alone should not serve as an absolute contraindication to LVAD therapy. ( $\mathrm{J}$ Thorac Cardiovasc Surg 2018;156:1093-101)

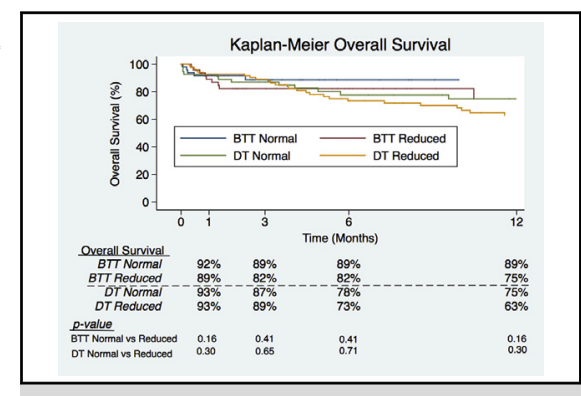

One-year survival after LVAD in DT and BTT patients with preimplantation renal dysfunction.

\section{Central Message}

Left ventricular assist devices can be implanted in patients with renal dysfunction with acceptable outcomes.

\section{Perspective}

Left ventricular assist devices will be implanted in a growing number of patients as the prevalence of end-stage heart failure increases with the aging population. Refining algorithms for patient selection particularly with higher risk cohorts such as those with renal dysfunction will be important to making this effective therapy available to more patients.

See Editorial Commentary page 1102.
Surgical options for end-stage heart failure continue to evolve. Heart transplantation offers the potential for longterm survival, with 20-year survival now a real possibility, however, its availability is limited by donor shortages.

\footnotetext{
From the a Division of Cardiac Surgery, University of Pittsburgh Medical Center, Pittsburgh, Pa; and Divisions of ${ }^{\mathrm{b}}$ Cardiovascular Surgery and ${ }^{\mathrm{c}}$ Cardiology, University of Pennsylvania, Philadelphia, $\mathrm{Pa}$.

Read at the International Society for Heart and Lung Transplantation Annual Meeting, San Diego, California, April 5-8, 2017.

Received for publication May 3, 2017; revisions received Oct 19, 2017; accepted for publication Dec 9, 2017; available ahead of print July 13, 2018.

Address for reprints: Pavan Atluri, MD, Division of Cardiovascular Surgery, University of Pennsylvania, 3400 Spruce St, Philadelphia, PA 19104 (E-mail: Pavan. Atluri@uphs.upenn.edu).

$0022-5223 / \$ 36.00$

Copyright (c) 2017 by The American Association for Thoracic Surgery

https://doi.org/10.1016/j.jtcvs.2017.12.044
}

Left ventricular assist devices (LVADs) can be implanted as destination therapy (DT) or as a bridge to transplantation (BTT). The use of LVADs in heart failure, acute and chronic, has increased and will likely continue to increase with the aging population, increases in prevalence of heart failure, improving technology, and better patient outcomes. $^{1,2}$ In cases of DT, 2-year survival of $80 \%$ can be achieved in select patients raising the question of when

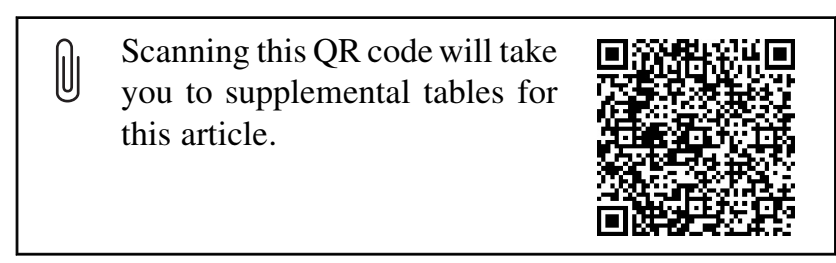




$\begin{array}{ll}\text { Abbreviations and Acronyms } \\ \text { BTT } & =\text { bridge to transplantation } \\ \text { CI } & =\text { confidence interval } \\ \text { DT } & =\text { destination therapy } \\ \text { ECMO } & \text { extracorporeal membrane } \\ & \text { oxygenation } \\ \text { HR } & =\text { hazard ratio } \\ \text { INTERMACS }= & \text { Interagency Registry for } \\ & \text { Mechanically Assisted Circulatory } \\ & \text { Support } \\ \text { LVAD } & =\text { left ventricular assist device } \\ \text { RVAD } & \text { right ventricular assist device }\end{array}$

long-term LVAD therapy should be pursued instead of heart transplantation, particularly in patients in whom the latter might not be a reality without a prolonged wait-list time. ${ }^{3}$

Although outcomes of LVAD therapy continue to improve, there are several barriers to its widespread application. Some areas are universally agreed upon. For instance, LVAD as DT is typically not an option in patients with fixed elevated pulmonary vascular resistance, those with a contraindication to anticoagulation, or in patients with severe right ventricular dysfunction preoperatively. Other areas, particularly as they relate to patient selection, remain controversial. One such area is preoperative renal function. Some groups argue that diminished renal function is a strong predictor of adverse outcomes after LVAD implantation and should be viewed as a contraindication to this therapy. ${ }^{4}$ Others argue that LVAD implantation improves renal function and can be performed with reasonable outcomes in this patient subset, and therefore, that preoperative renal dysfunction should not be an exclusion criteria for LVADs. ${ }^{5}$ In this study, we review our experience with LVAD implantation for DT and BTT in patients with preoperative renal dysfunction.

\section{METHODS}

\section{Study Population}

The study population included all LVAD implantations as DT or BTT at a single institution between January 1, 2006 and December 31, 2015. All LVADs in this analysis were continuous flow LVADs with most $(79 \%$; $\mathrm{n}=187$ ) being HeartMate II (Thoratec Corporation, Pleasanton, Calif). Pediatric patients (younger than 18 years) were excluded. Patients were stratified according to DT versus BTT and preimplantation glomerular filtration rate (GFR): $>60 \mathrm{~mL} / \mathrm{min}$ (normal) versus $<60 \mathrm{~mL} / \mathrm{min}$ or dialysis dependence (reduced GFR). GFR was calculated using the Cockcroft-Gault formula. The institutional review board granted this study exempt status.

\section{Baseline Characteristics}

Baseline characteristics were compared between the normal and reduced GFR groups for DT and BTT. Preoperative variables included age, sex, race, weight, height, body mass index, ejection fraction, hemodynamics (heart rate, systolic and diastolic blood pressure, mean arterial pressure, central venous pressure, pulmonary artery pressures, cardiac index, systemic venous oxygen saturation, wedge pressure, pulmonary vascular resistance, right ventricular stroke work index), comorbidities (coronary artery disease, pulmonary hypertension, chronic obstructive pulmonary disease, diabetes mellitus, smoking, hypertension, hypercholesterolemia, atrial fibrillation, carotid stenosis, cerebrovascular disease, gastrointestinal bleed, thromboembolism, previous myocardial infarction), and laboratory parameters (white blood cell count, hemoglobin, platelet count, blood urea nitrogen, creatinine, sodium, potassium, chloride, carbon dioxide, alanine transaminase, aspartate transaminase, total bilirubin, bicarbonate, lactate, albumin, pre-albumin, international normalized ratio, partial thromboplastin time, lactate dehydrogenase, hemoglobin A1c). Other variables included etiology of heart failure, previous open-heart surgery, milrinone or other inotropic dependence, mechanical ventilation, bridge with extracorporeal membrane oxygenation (ECMO), Interagency Registry for Mechanically Assisted Circulatory Support (INTERMACS) category, need for intraoperative right ventricular assist device (RVAD), and concomitant procedures such as coronary artery bypass grafting or valve repair or replacement.

\section{Outcomes}

The primary outcome was post-LVAD implantation overall survival. Secondary outcomes included major postoperative complications such as re-exploration for bleeding, stroke, reintubation, sepsis, pneumonia, gastrointestinal bleed, acute renal failure requiring dialysis, and arrhythmias. Other secondary outcomes were rates of transplantation in the BTT group and recovery of renal function to a GFR $>60 \mathrm{~mL} / \mathrm{min}$ in the patients with reduced pre-LVAD implantation GFR. GFR was measured at baseline and at 3,6, and 12 months post-LVAD implantation.

\section{Data Analysis}

Kaplan-Meier analyses were conducted to compare the overall postLVAD implantation survival between the normal and reduced GFR cohorts after stratification on the basis of DT versus BTT. Survival curves were compared using the log rank test. Multivariable Cox regression analyses incorporating univariate predictors (inclusion criteria of 2-tailed $P<.05$ ) were conducted to evaluate the risk-adjusted effect of reduced GFR on post-LVAD implantation mortality. GFR was modeled as a continuous and a categorical variable in these Cox analyses. Lowess smoothing plots were also constructed to visually depict thresholds of GFR below which the most significant improvements in post-LVAD implantation GFR would be obtained. All continuous data are presented as mean \pm SD and all categorical data as number (percentage). Continuous data were compared with $\chi 2$ and categorical data with Student $t$ test. All statistical analyses were performed with version 11 STATA software (StataCorp LP, College Station, Tex).

\section{RESULTS \\ Baseline Characteristics}

A total of 273 patients underwent LVAD implantation at our institution during the study period, including 238 who underwent implantation as DT $(60 \% ; \mathrm{n}=142)$ or BTT $(40 \% ; \mathrm{n}=96)$. In the DT cohort, the patients with normal and reduced GFR were well matched with the exception of the reduced GFR patients being older, having more atrial fibrillation, having a lower preoperative hemoglobin level, higher preoperative blood urea nitrogen level, more concomitant tricuspid valve procedures, and using more frequent use of aortic cross-clamp (Table 1). Most LVADs in the DT cohort were implanted for ischemic cardiomyopathy, with most patients being INTERMACS 2 or 3 . 
TABLE 1. Comparison of baseline characteristics of the normal and reduced renal function cohorts in destination therapy patients

\begin{tabular}{|c|c|c|c|}
\hline Variable & Normal GFR $(n=54)$ & Reduced GFR $(\mathbf{n}=85)$ & $P$ value \\
\hline \multicolumn{4}{|l|}{ Patient } \\
\hline $\mathrm{GFR}, \mathrm{mL} / \mathrm{min}$ & $80 \pm 19$ & $43 \pm 11$ & $<.001$ \\
\hline Age, y & $57 \pm 16$ & $64 \pm 10$ & .002 \\
\hline Male sex & $44(81 \%)$ & $74(87 \%)$ & .37 \\
\hline Body mass index & $29 \pm 8$ & $29 \pm 6$ & .59 \\
\hline Caucasian & $34(63 \%)$ & $52(61 \%)$ & .27 \\
\hline Diabetes mellitus & $23(43 \%)$ & $41(48 \%)$ & .52 \\
\hline Hypertension & $32(59 \%)$ & $56(67 \%)$ & .33 \\
\hline Cerebrovascular disease & $11(20 \%)$ & $9(11 \%)$ & .11 \\
\hline Chronic obstructive pulmonary disease & $13(24 \%)$ & $18(21 \%)$ & .69 \\
\hline Coronary artery disease & $31(57 \%)$ & $56(66 \%)$ & .31 \\
\hline Myocardial infarction & $26(48 \%)$ & $34(40 \%)$ & .34 \\
\hline Pulmonary hypertension & $21(39 \%)$ & $30(36 \%)$ & .71 \\
\hline Smoking & $27(51 \%)$ & $43(51 \%)$ & .98 \\
\hline Hypercholesterolemia & $37(70 \%)$ & $60(71 \%)$ & .84 \\
\hline Atrial fibrillation & $21(39 \%)$ & $53(62 \%)$ & .007 \\
\hline Gastrointestinal bleed & $2(4 \%)$ & $6(9 \%)$ & .36 \\
\hline Ventricular arrhythmias & $24(51 \%)$ & $33(46 \%)$ & .63 \\
\hline Thromboembolism & $3(6 \%)$ & $3(4 \%)$ & .63 \\
\hline Carotid stenosis & $3(6 \%)$ & $9(11 \%)$ & .31 \\
\hline Previous open-heart surgery & $22(42 \%)$ & $35(41 \%)$ & .97 \\
\hline Etiology of heart failure & & & .30 \\
\hline Ischemic & $31(58 \%)$ & $45(54 \%)$ & \\
\hline Idiopathic & $16(30 \%)$ & $32(39 \%)$ & \\
\hline Other & $6(11 \%)$ & $6(7 \%)$ & \\
\hline INTERMACS category & & & .79 \\
\hline 1 & $3(6 \%)$ & $4(5 \%)$ & \\
\hline 2 & $21(45 \%)$ & $31(42 \%)$ & \\
\hline 3 & $14(30 \%)$ & $27(37 \%)$ & \\
\hline 4 & $9(19 \%)$ & $10(14 \%)$ & \\
\hline 5 & $0(0 \%)$ & $1(1 \%)$ & \\
\hline Mechanical ventilation & $2(4 \%)$ & $7(8 \%)$ & .31 \\
\hline Extracorporeal membrane oxygenation & $2(4 \%)$ & $1(1 \%)$ & .31 \\
\hline Intra-aortic balloon pump & $6(11 \%)$ & $7(8 \%)$ & .55 \\
\hline \multicolumn{4}{|l|}{ Hemodynamics } \\
\hline Left ventricular ejection fraction, $\%$ & $15.4 \pm 6.9$ & $16.6 \pm 5.7$ & .28 \\
\hline Pulmonary vascular resistance, Wood units & $3.5 \pm 1.8$ & $3.1 \pm 1.7$ & .45 \\
\hline Central venous pressure, $\mathrm{mm} \mathrm{Hg}$ & $8.6 \pm 5.0$ & $9.8 \pm 5.5$ & .22 \\
\hline Right ventricular stroke work index, $\mathrm{g} / \mathrm{m}^{2}$ per beat & $8.0 \pm 4.6$ & $8.4 \pm 4.0$ & .69 \\
\hline \multicolumn{4}{|l|}{ Laboratory data } \\
\hline White blood cell count & $7.6 \pm 2.6$ & $7.9 \pm 4.3$ & .66 \\
\hline Hemoglobin & $11.3 \pm 1.8$ & $10.6 \pm 1.8$ & .03 \\
\hline Platelet count & $177 \pm 64$ & $180 \pm 60$ & .78 \\
\hline Blood urea nitrogen & $19.8 \pm 8.9$ & $41.0 \pm 18.1$ & $<.001$ \\
\hline Serum creatinine, $\mathrm{mg} / \mathrm{dL}$ & $1.0 \pm 0.2$ & $1.8 \pm 0.5$ & $<.001$ \\
\hline Serum sodium & $135 \pm 4$ & $136 \pm 4$ & .68 \\
\hline Serum bilirubin & $1.1 \pm 0.4$ & $1.3 \pm 0.7$ & .18 \\
\hline Lactate & $1.1 \pm 0.4$ & $1.1 \pm 0.6$ & .90 \\
\hline Albumin & $3.5 \pm 0.5$ & $3.8 \pm 2.7$ & .50 \\
\hline International normalized ratio & $1.8 \pm 1.9$ & $1.5 \pm 0.5$ & .21 \\
\hline \multicolumn{4}{|l|}{ Surgical } \\
\hline \multicolumn{4}{|l|}{ Concomitant procedures } \\
\hline CABG & $1(2 \%)$ & $1(1 \%)$ & .73 \\
\hline Tricuspid valve repair or replacement & $1(2 \%)$ & $9(11 \%)$ & .05 \\
\hline
\end{tabular}


TABLE 1. Continued

\begin{tabular}{llll}
\hline \multicolumn{1}{c}{ Variable } & Normal GFR $(\mathbf{n}=\mathbf{5 4})$ & Reduced GFR $(\mathbf{n}=\mathbf{8 5})$ & \multicolumn{1}{c}{$\boldsymbol{P}$ value } \\
\hline Mitral valve repair or replacement & $0(0 \%)$ & $2(2 \%)$ & .26 \\
Aortic valve repair or replacement & $3(6 \%)$ & $10(12 \%)$ & .24 \\
Cardiopulmonary bypass time, minutes & $79.8 \pm 52.9$ & $92.5 \pm 45.7$ & .14 \\
Use of aortic cross-clamp & $4(7 \%)$ & $19(22 \%)$ & .02 \\
Aortic cross-clamp time, minutes & $47.0 \pm 25.1$ & $58.4 \pm 34.3$ & .54 \\
Intraoperative insertion of temporary right ventricular assist device & $6(11 \%)$ & $6(7 \%)$ & .41 \\
\hline
\end{tabular}

Normal GFR was defined as $>60 \mathrm{~mL} / \mathrm{min}$ and reduced GFR as $<60 \mathrm{~mL} / \mathrm{min}$ or dialysis dependence. Categorical data are presented as number (percentage) and continuous data as mean \pm standard deviation. GFR, Glomerular filtration rate; INTERMACS, Interagency Registry for Mechanically Assisted Circulatory Support; CABG, coronary artery bypass grafting.

Concomitant procedures were performed infrequently $(<12 \%)$ and temporary RVADs were required at the time of LVAD implantation in $9 \%$ of cases.

In the BTT group, the patients with normal and reduced GFR were also relatively well matched with the exception of the reduced GFR patients being older, having more hypertension, more history of myocardial infarction, more atrial fibrillation, higher preoperative blood urea nitrogen level, and lower rate of bridging with ECMO (Table 2). Unlike the DT group, most patients in the BTT group had nonischemic cardiomyopathy as the underlying etiology of their heart failure. Most patients were INTERMACS 2, with more INTERMACS 1 patients than in the DT cohort. Concomitant procedures were performed even less frequently in the BTT group (4\%), with temporary RVAD support required in $9 \%$.

\section{Kaplan-Meier Survival Analysis}

The mean follow-up in the DT cohort was $16.5 \pm 18.0$ months, and was similar between patients with normal and reduced GFR $(P=.87)$. Overall survival rates at last follow-up were comparable at $64.8 \%$ (normal GFR) versus $54.1 \%$ (reduced GFR; $P=.21$ ). KaplanMeier 1-, 3-, 6-, and 12-month survival was similar between patients with normal and reduced GFR (Figure 1 and Table E1).

The mean follow-up in the BTT cohort was $9.1 \pm 14.3$ months, and was similar between the normal and reduced GFR groups $(P=.64)$. Overall survival at last follow-up was comparable: $87.7 \%$ and $76.6 \%$ in the patients with normal and reduced GFR, respectively $(P=.15)$. Kaplan-Meier 1-, 3-, 6-, and 12-month survival estimates were similar between the normal and reduced GFR groups (Figure 1 and Table E1).

\section{Multivariable Cox Regression Analysis}

A total of 6 variables (excluding reduced GFR) met entry criteria for the multivariable Cox regression model for overall mortality after LVAD implantation in the DT cohort (Table 3). Reduced GFR was not found to affect overall post-LVAD implantation mortality (hazard ratio [HR], $1.10 ; 95 \%$ confidence interval $[\mathrm{CI}], 0.60-2.03 ; P=.76$ ).
The same finding persisted when decreasing GFR was modeled as a continuous variable (HR, 1.01; 95\% CI, $0.99-1.03 ; P=.19$ ). Because age is a component of GFR, a model was also run excluding it and reduced GFR remained a nonpredictor (HR, 1.17; 95\% CI, 0.64-2.13; $P=.60$ ). The only significant independent predictor of post-LVAD implantation overall mortality was the need for temporary RVAD support at the time of LVAD implantation (HR, 3.56; 95\% CI, 1.55-8.18; $P=.003$ ).

In the BTT cohort, 8 variables excluding reduced GFR met entry criteria for the multivariable Cox regression model (Table 4). Predictors of post-LVAD implantation overall mortality included pre-LVAD implantation intraaortic balloon pump (HR, 7.57; 95\% CI, 1.45-39.5; $P=.02$ ), lower preoperative platelet count (HR, 1.01; $95 \%$ CI, $1.00-1.03 ; P=.03$ ), higher preoperative total bilirubin (HR, $1.88 ; 95 \% \mathrm{CI}, 1.07-3.32 ; P=.03$ ), and the need for temporary RVAD support at the time of LVAD implantation (HR, 23.3; 95\% CI, 4.78-113.8; $P<.001$ ). Reduced preoperative GFR did not affect the risk of post-LVAD implantation mortality (HR, 1.33; 95\% CI, 0.26-6.66; $P=.73$ ). The same finding persisted when decreasing GFR was modeled as a continuous variable (HR, 1.00; 95\% CI, 0.97-1.04; $P=.77$ ). When DT and BTT patients were included in the same multivariable Cox regression model and univariate analysis rerun to identify predictors, decreasing GFR was again not associated with mortality risk (HR, 0.99; 95\% CI, 0.95-1.02; $P=.37$ ).

\section{Secondary Outcomes}

In the DT cohort, survival to hospital discharge was comparable between the normal GFR $(88.9 \%)$ and reduced GFR $(87.1 \%)$ groups $(P=.75)$. There was a trend toward longer mean intensive care unit stay in the reduced GFR group (normal $11.2 \pm 18.1$ days vs reduced $16.8 \pm 17.6$ days; $P=.08$ ). Rates of reoperation for bleeding $(16.7 \%$ vs $26.2 \% ; P=.19)$, reintubation $(16.7 \%$ vs $20.2 \% ; P=.60)$, driveline infection $(3.8 \%$ vs $3.6 \% ; P=.95)$, sepsis $(5.6 \%$ vs $11.8 \% ; P=.22)$, pneumonia $(16.7 \%$ vs $8.7 \% ; P=.19)$, and new-onset arrhythmia $(21.7 \%$ vs $16.2 \% ; P=.45)$ were similar. There were trends toward higher rates of stroke $(1.9 \%$ vs $9.5 \%$; 
TABLE 2. Comparison of baseline characteristics between the normal and reduced renal function cohorts in bridge to transplantation patients

\begin{tabular}{|c|c|c|c|}
\hline Variable & Normal GFR $(n=49)$ & Reduced GFR $(n=47)$ & $P$ value \\
\hline \multicolumn{4}{|l|}{ Patient } \\
\hline Glomerular filtration rate, $\mathrm{mL} / \mathrm{min}$ & $96 \pm 32$ & $45 \pm 11$ & $<.001$ \\
\hline Age, y & $46 \pm 15$ & $54 \pm 9$ & .002 \\
\hline Male sex & $38(78 \%)$ & $35(74 \%)$ & .72 \\
\hline Body mass index & $29 \pm 7$ & $30 \pm 6$ & .70 \\
\hline Caucasian & $26(53 \%)$ & $23(49 \%)$ & .64 \\
\hline Diabetes mellitus & $19(39 \%)$ & $27(57 \%)$ & .07 \\
\hline Hypertension & $22(46 \%)$ & $33(72 \%)$ & .01 \\
\hline Cerebrovascular disease & $6(12 \%)$ & $9(19 \%)$ & .35 \\
\hline Chronic obstructive pulmonary disease & $6(13 \%)$ & $3(6 \%)$ & .31 \\
\hline Coronary artery disease & $18(37 \%)$ & $25(53 \%)$ & .11 \\
\hline Myocardial infarction & $9(18 \%)$ & $17(36 \%)$ & .05 \\
\hline Pulmonary hypertension & $15(31 \%)$ & $19(40 \%)$ & .32 \\
\hline Smoking & $21(43 \%)$ & $19(40 \%)$ & .81 \\
\hline Hypercholesterolemia & $28(57 \%)$ & $32(68 \%)$ & .27 \\
\hline Atrial fibrillation & $12(24 \%)$ & $21(45 \%)$ & .04 \\
\hline Gastrointestinal bleed & $2(7 \%)$ & $2(6 \%)$ & .97 \\
\hline Ventricular arrhythmias & $15(15 \%)$ & $21(66 \%)$ & .21 \\
\hline Thromboembolism & $2(7 \%)$ & $5(16 \%)$ & .27 \\
\hline Carotid stenosis & $2(4 \%)$ & $5(11 \%)$ & .22 \\
\hline Previous open-heart surgery & $16(33 \%)$ & $14(30 \%)$ & .76 \\
\hline Etiology of heart failure & & & .27 \\
\hline Ischemic & $14(29 \%)$ & $21(45 \%)$ & \\
\hline Idiopathic & $25(51 \%)$ & $25(53 \%)$ & \\
\hline Other & $10(20 \%)$ & $1(2 \%)$ & \\
\hline INTERMACS Category & & & .87 \\
\hline 1 & $11(25 \%)$ & $8(20 \%)$ & \\
\hline 2 & $21(48 \%)$ & $21(53 \%)$ & \\
\hline 3 & $10(23 \%)$ & $8(20 \%)$ & \\
\hline 4 & $2(5 \%)$ & $3(8 \%)$ & \\
\hline Mechanical ventilation & $5(10 \%)$ & $3(6 \%)$ & .50 \\
\hline Extracorporeal membrane oxygenation & $4(8 \%)$ & $0(0 \%)$ & .05 \\
\hline Intra-aortic balloon pump & $6(12 \%)$ & $7(15 \%)$ & .71 \\
\hline \multicolumn{4}{|l|}{ Hemodynamics } \\
\hline Left ventricular ejection fraction, $\%$ & $14.5 \pm 9.0$ & $15.9 \pm 7.1$ & .39 \\
\hline Pulmonary vascular resistance, Wood units & $3.1 \pm 1.5$ & $3.1 \pm 1.6$ & .93 \\
\hline Central venous pressure, $\mathrm{mm} \mathrm{Hg}$ & $11.0 \pm 8.0$ & $10.1 \pm 6.3$ & .57 \\
\hline Right ventricular stroke work index, $\mathrm{g} / \mathrm{m}^{2}$ per beat & $7.2 \pm 4.9$ & $7.8 \pm 4.3$ & .54 \\
\hline \multicolumn{4}{|l|}{ Laboratory data } \\
\hline White blood cell count & $8.3 \pm 3.5$ & $8.9 \pm 3.5$ & .45 \\
\hline Hemoglobin & $11.6 \pm 2.1$ & $10.9 \pm 1.9$ & .09 \\
\hline Platelet count & $202 \pm 79$ & $213 \pm 83$ & .52 \\
\hline Blood urea nitrogen & $19.1 \pm 9.8$ & $32.5 \pm 19.0$ & $<.001$ \\
\hline Serum creatinine, $\mathrm{mg} / \mathrm{dL}$ & $1.0 \pm 0.2$ & $1.7 \pm 0.5$ & $<.001$ \\
\hline Serum sodium & $134 \pm 6$ & $134 \pm 4$ & .95 \\
\hline Serum bilirubin & $1.2 \pm 0.8$ & $1.6 \pm 1.2$ & .13 \\
\hline Lactate & $1.2 \pm 0.5$ & $0.8 \pm 0.3$ & .07 \\
\hline Albumin & $3.5 \pm 0.7$ & $3.4 \pm 0.5$ & .57 \\
\hline International normalized ratio & $1.3 \pm 0.3$ & $1.4 \pm 0.4$ & .20 \\
\hline \multicolumn{4}{|l|}{ Surgical } \\
\hline \multicolumn{4}{|l|}{ Concomitant procedures } \\
\hline CABG & $0(0 \%)$ & $0(0 \%)$ & .99 \\
\hline Tricuspid valve repair or replacement & $2(4 \%)$ & $1(2 \%)$ & .58 \\
\hline Mitral valve repair or replacement & $0(0 \%)$ & $0(0 \%)$ & .99 \\
\hline
\end{tabular}


TABLE 2. Continued

\begin{tabular}{|c|c|c|c|}
\hline Variable & Normal GFR $(n=49)$ & Reduced GFR $(n=47)$ & $P$ value \\
\hline Aortic valve repair or replacement & $1(2 \%)$ & $0(0 \%)$ & .33 \\
\hline Cardiopulmonary bypass time, minutes & $87.2 \pm 49.9$ & $93.6 \pm 46.0$ & .52 \\
\hline Use of aortic cross-clamp & $4(8 \%)$ & $4(9 \%)$ & .95 \\
\hline Aortic cross-clamp time, minutes & $59.8 \pm 53.1$ & $39.3 \pm 25.4$ & .51 \\
\hline Intraoperative insertion of temporary right ventricular assist device & $5(10 \%)$ & $4(9 \%)$ & .78 \\
\hline
\end{tabular}

GFR, Glomerular filtration rate; INTERMACS, Interagency Registry for Mechanically Assisted Circulatory Support; CABG, coronary artery bypass grafting.

$P=.08)$ and gastrointestinal bleed $(7.6 \%$ vs $18.8 \%$; $P=.07)$ in the reduced GFR cohort. The rates of newonset postoperative dialysis were comparable between the normal $(11.1 \%)$ and reduced preoperative GFR $(12.2 \%)$ cohorts $(P=.86)$.

Survival to hospital discharge was comparable between the patients with normal and reduced GFR in the BTT cohort $(87.8 \%$ vs $82.6 \%$, respectively; $P=.48)$. Length of intensive care unit stay was comparable between the normal GFR $(8.5 \pm 7.5$ days $)$ and reduced GFR $(11.0 \pm 9.1$ days $)$ groups $(P=.16)$. Reoperation for bleeding $(16.3 \%$ vs $24.4 \% ; P=.33)$, stroke $(6.1 \%$ vs $8.7 \% ; P=.63)$, pneumonia $(3.1 \%$ vs $12.1 \% ; P=.17)$, gastrointestinal bleeding $(4.1 \%$ vs $13.0 \% ; P=.12)$, and new-onset dialysis $(2.0 \%$ vs $7.7 \% ; P=.21)$ were similar between patients with normal and reduced GFR, respectively. New-onset arrhythmia rates were lower in the reduced GFR cohort (32.3\% normal GFR vs 3.3\% reduced GFR; $P=.003)$. There was a trend toward higher rates of reintubation $(10.2 \%$ vs $24.4 \% ; P=.07)$, driveline infection $(2.0 \%$ vs $10.9 \% ; P=.08)$, and sepsis $(2.0 \%$ vs $11.1 \%$; $P=.07)$ in the reduced GFR group. Rates of transplantation

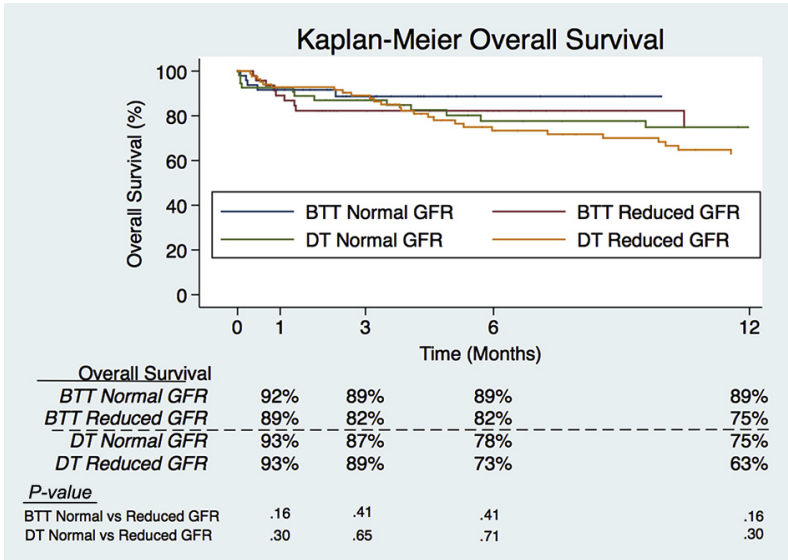

FIGURE 1. Post left ventricular assist device implantation survival rates, stratified according to preoperative renal function and destination therapy (DT) versus bridge to transplantation (BTT). The number of patients at risk and $95 \%$ confidence intervals are provided in Table E1. GFR, Glomerular filtration rate. were comparable in BTT patients $(61 \%$ normal vs $53 \%$ reduced GFR; $P=.43$ ).

Renal function recovered significantly in DT and BTT patients with reduced preoperative GFR after LVAD implantation (Figure 2 and Table E2). The most significant improvement for both groups was in the first 3 months after LVAD implantation after which mean GFR slightly declined, although it still remained significantly better than baseline at the 6- and 12-month follow-up postLVAD implantation. Overall, recovery of renal function to a GFR $>60 \mathrm{~mL} / \mathrm{min}$ occurred in $43 \%(\mathrm{n}=17)$ and $57 \%$ $(\mathrm{n}=42)$ of patients with reduced GFR in the BTT and DT cohorts, respectively, by 1-year after implantation. Although a higher percentage of patients in the DT cohort with reduced GFR improved to normal renal function, the overall degree of improvement was more pronounced in the BTT patients (Figure 2 and Table E2). Lowess smoothing plots showed a linear breakpoint of $40 \mathrm{~mL} / \mathrm{min}$ as a baseline GFR below which the most significant improvements in postoperative GFR were obtained at 6 and 12 months post-LVAD implantation (Figure 3).

There were 18 patients (7 BTT and $11 \mathrm{DT}$ ) that were receiving dialysis preoperatively. The 12-month survival in these patients was $71 \%$ and $45 \%$ in the BTT and DT groups, respectively. Length of intensive care unit stay was $31 \pm 26$ days. The rate of reoperation for bleeding was $22 \%$, pneumonia $19 \%$, and sepsis $22 \%$. There were 19 patients who required de novo dialysis postoperatively (4 BTT and 15 DT). Hospital survival was $47 \%$ in these patients, with a 1-year survival of only $17 \%$. Length of intensive care unit stay was $30 \pm 32$ days. Complication rates included reoperation for bleeding $(61 \%)$, pneumonia $(19 \%)$, and sepsis $(22 \%)$.

\section{DISCUSSION \\ Study Findings}

In this study we reviewed our single-center experience with LVAD implantation as DT and BTT in patients with compromised renal function. The principal finding was that outcomes were acceptable and in general comparable with those with normal preoperative renal function. Furthermore, renal function improved significantly post-LVAD implantation in those with reduced GFR preoperatively, with approximately one-half of patients recovering to a GFR 
TABLE 3. Cox regression model for overall mortality after LVAD in destination therapy patients

\begin{tabular}{lcccc}
\hline \multicolumn{1}{c}{ Covariates } & $\begin{array}{c}\text { Univariate HR } \\
(\mathbf{9 5} \% \mathbf{C I})\end{array}$ & $\begin{array}{c}\text { Univariate } \\
\boldsymbol{P} \text { value }\end{array}$ & $\begin{array}{c}\text { Multivariate HR } \\
(\mathbf{9 5} \% \mathbf{~ C I})\end{array}$ & $\begin{array}{c}\text { Multivariate } \\
\boldsymbol{P} \text { value }\end{array}$ \\
\hline Reduced GFR* & $1.33(0.77-2.32)$ & .31 & $1.10(0.60-2.03)$ & .76 \\
Age (increasing) & $1.02(1.00-1.05)$ & .04 & $1.02(0.99-1.05)$ & .19 \\
Preoperative hemoglobin (decreasing) & $1.16(1.03-1.29)$ & .02 & $1.13(0.95-1.35)$ & .16 \\
Cardiopulmonary bypass time (increasing) & $1.01(1.00-1.01)$ & .04 & $1.00(0.99-1.01)$ & .57 \\
Concomitant tricuspid valve surgery & $2.81(1.19-6.61)$ & .02 & $2.50(0.96-6.50)$ & .06 \\
Previous open-heart surgery & $1.76(1.03-3.01)$ & .04 & $1.41(0.75-2.65)$ & .28 \\
Intraoperative temporary right ventricular assist device insertion & $2.88(1.29-6.40)$ & .01 & $3.56(1.55-8.18)$ & .003 \\
\hline
\end{tabular}

HR, Hazard ratio; $C I$, confidence interval; GFR, glomerular filtration rate. *Decreasing GFR remained a nonpredictor of mortality when modeled as a continuous variable with a hazard ratio of 1.01 (95\% CI, 0.99-1.03); $P=.19$.

$>60 \mathrm{~mL} / \mathrm{min}$ by 1 -year post-LVAD implantation. Collectively, these data suggest that compromised preoperative renal function alone should not be an absolute contraindication to LVAD implantation.

\section{Risk Factors for Mortality}

Not unexpectedly the requirement for temporary RVAD support at the time of LVAD implantation was the strongest risk factor for post-LVAD implantation mortality in the DT and BTT cohorts. In the sixth INTERMACS annual report of 10,542 patients implanted with LVADs, RVAD in the same surgery was most strongly associated with early mortality. ${ }^{6}$ Predicting the need for biventricular support preoperatively is therefore essential to patient selection and prognosis. Several models have been developed using a combination of patient variables, echocardiographic measurements, laboratory parameters, and hemodynamic data to predict the need for concomitant RVAD implantation during LVAD surgery. ${ }^{7-10}$

Lower preoperative platelet count and higher preoperative total bilirubin levels were also associated with increased mortality after LVAD implantation in the BTT cohort with reduced GFR. These findings are also not surprising. Previous analyses have shown decreased platelet count to correlate with post-LVAD mortality in the shortand longer-term in multivariable analyses. ${ }^{11,12} \mathrm{~A}$ study of 1149 continuous-flow LVAD recipients reported that increasing preoperative bilirubin levels correlated with increased 1-year mortality after implantation. ${ }^{13}$

\section{Previous Analyses of LVAD Implantation in Patients With Renal Dysfunction}

Although some multivariable models to assess mortality after LVAD insertion have identified preoperative renal function as an independent predictor, others have not. ${ }^{14-16}$ A study of 86 LVAD implantations showed a $25 \%$ lower rate of 6-month post-LVAD implantation survival in those with a GFR $<60 \mathrm{~mL} / \mathrm{min}$. ${ }^{14}$ Another study showed that preoperative serum creatinine level was an independent predictor of 90-day mortality after LVAD implantation in INTERMACS 1 patients. ${ }^{15}$ An INTERMACS analysis showed reduced survival that was most pronounced in the first 3 months after LVAD therapy in patients with renal dysfunction, particularly when severe and coupled with

TABLE 4. Cox regression model for overall mortality after LVAD in bridge to transplantation patients

\begin{tabular}{|c|c|c|c|c|}
\hline Covariates & $\begin{array}{c}\text { Univariate HR } \\
(95 \% \mathrm{CI})\end{array}$ & $\begin{array}{c}\text { Univariate } \\
P \text { value }\end{array}$ & $\begin{array}{c}\text { Multivariate HR } \\
(95 \% \text { CI })\end{array}$ & $\begin{array}{c}\text { Multivariate } \\
P \text { value }\end{array}$ \\
\hline Reduced GFR* & $2.09(0.72-6.03)$ & .17 & $1.33(0.26-6.66)$ & .73 \\
\hline Acute myocardial infarction & $3.69(1.01-13.5)$ & .04 & $2.71(0.41-18.1)$ & .30 \\
\hline Pre-LVAD intra-aortic balloon pump & $7.13(2.44-20.8)$ & $<.001$ & $7.57(1.45-39.5)$ & .02 \\
\hline Preoperative white blood cell count (increasing) & $1.17(1.05-1.30)$ & .006 & $0.97(0.80-1.17)$ & .72 \\
\hline Preoperative platelet count (decreasing) & $1.01(1.00-1.01)$ & .05 & $1.01(1.00-1.03)$ & .03 \\
\hline Preoperative blood urea nitrogen (increasing) & $1.02(1.00-1.04)$ & .04 & $1.00(0.97-1.04)$ & .82 \\
\hline Preoperative AST (increasing) & $1.00(1.00-1.01)$ & .004 & $1.00(0.99-1.01)$ & .47 \\
\hline Preoperative total bilirubin (increasing) & $1.36(1.07-1.75)$ & .01 & $1.88(1.07-3.32)$ & .03 \\
\hline Cardiopulmonary bypass time (increasing) & $1.01(1.00-1.02)$ & .04 & $1.01(0.99-1.02)$ & .25 \\
\hline Intraoperative temporary right ventricular assist device insertion & $9.23(2.24-38.0)$ & .002 & $23.3(4.78-113.8)$ & $<.001$ \\
\hline
\end{tabular}

$H R$, Hazard ratio; $C I$, confidence interval; $G F R$, glomerular filtration rate; $A S T$, aspartate aminotransferase. *Decreasing GFR remained a nonpredictor of mortality when modeled as a continuous variable with a hazard ratio of $1.00(95 \% \mathrm{CI}, 0.97-1.04) ; P=.77$. 


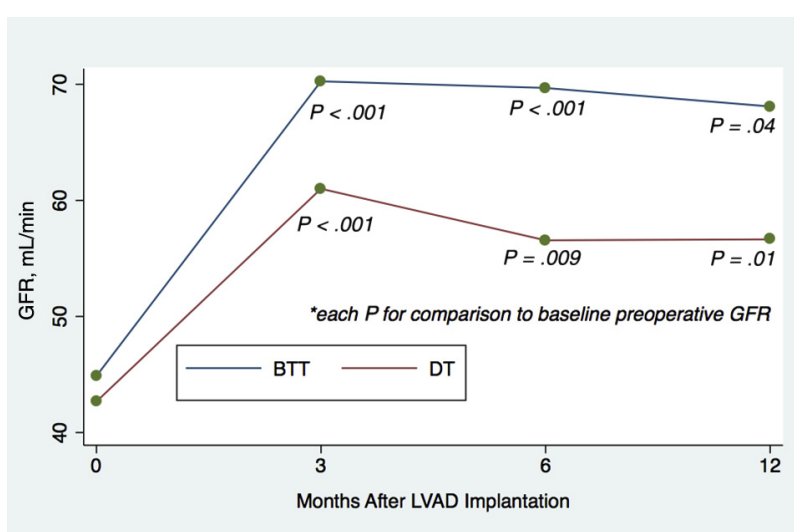

FIGURE 2. Changes in mean glomerular filtration rate $(G F R)$ after left ventricular assist device (LVAD) implantation. The number of patients at risk and $95 \%$ confidence intervals are provided in Table E2. BTT, Bridge to transplantation; $D T$, destination therapy.

cardiogenic shock. ${ }^{16}$ In contradistinction, an analysis of 415 patients showed that although post-LVAD implantation renal failure was a predictor of in-hospital and 30-day mortality, preoperative renal failure did not affect either of these outcomes. ${ }^{17}$

With respect to changes in renal function after LVAD implantation, we found that $43 \%$ of BTT and $57 \%$ of DT patients with reduced preoperative GFR improved to a GFR of at least $60 \mathrm{~mL} / \mathrm{min}$ by 1 -year post implantation. As depicted in Figure 2, both groups substantially improved mean GFR in the first 3 months and then subsequently experienced a slight decline and plateauing of GFR, although each of the mean GFR values at follow-up were significantly better than the baseline GFR. Similar findings have been shown by multiple groups. ${ }^{18-22}$ One study included 116 patients supported with ventricular assist devices, of which $72 \%$ were LVADs and $>90 \%$ were used as BTT. ${ }^{18}$ The creatinine clearance improved significantly for the overall group after initiation of mechanical circulatory support, with improvements continuing to beyond 6 months post implantation. Furthermore, the most substantial improvements in renal function were in patients with the lowest preimplantation creatinine clearances. Similarly, another study of 83 LVAD recipients showed significant improvements in GFR after LVAD implantation particularly in patients with reduced preimplantation GFR $<60 \mathrm{~mL} / \mathrm{min} .{ }^{19}$ In the group with reduced GFR before implantation, $67 \%$ of those surviving to 1 month post-LVAD implantation improved their GFR to $>60 \mathrm{~mL} / \mathrm{min}$.

An analysis examining hepatorenal function in LVAD recipients showed early improvement followed by a plateau phase, with minimal need for permanent hemodialysis. ${ }^{20}$ Other studies focused on patients with preoperative renal dysfunction similarly reported that even patients with severely reduced preoperative GFR improve renal function with LVAD support. ${ }^{21,22}$ Data from these studies as well as ours suggest that most cases of renal dysfunction before LVAD implantation are reversible and likely related to poor perfusion that is responsive to improved blood flow with LVAD support.

\section{Selection of Patients With Reduced GFR for LVAD Therapy}

The ultimate criteria used to select candidates for LVAD support varies between institutions and providers. With regard to heart failure patients with reduced renal function, our general approach has been to consider the presence of other high-risk factors before deciding on the treatment modality. For example, we would be more likely to use ECMO as a bridge in a patient who is INTERMACS 1 , receiving multiple high-dose inotropes, intubated, and with evidence of liver malperfusion in addition to renal dysfunction. On
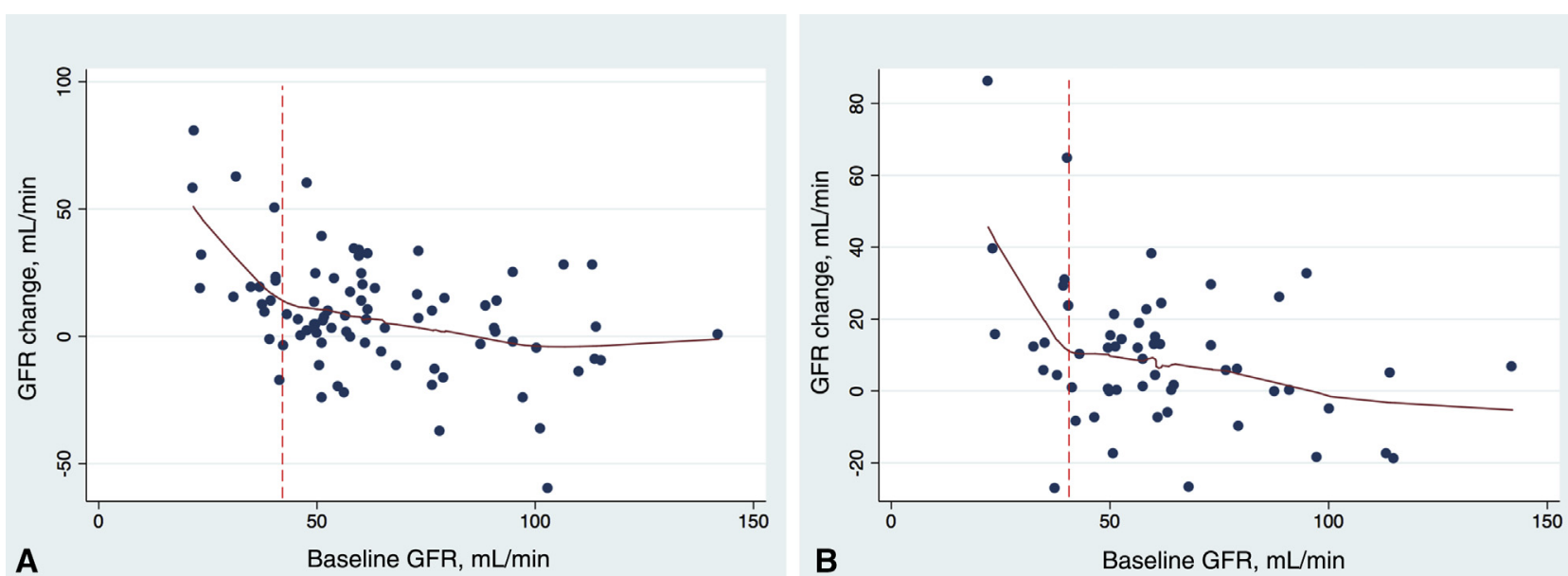

FIGURE 3. Lowess smoothing plots showing changes in glomerular filtration rate (GFR) at (A) 6 months and (B) 12 months after left ventricular assist device implantation on the basis of baseline GFR. 
the other end of the spectrum, a patient with a reduced preoperative GFR of $30 \mathrm{~mL} / \mathrm{min}$, but who is an outpatient and INTERMACS 3, we would offer LVAD therapy assuming that they do not have any of the other usual contraindications that are typically evaluated. In the cases of preoperative dialysis, we are much more selective in using LVAD therapy and favorable criteria in these cases would include reversibility of renal dysfunction determined by potential biopsies and consultation with nephrology, absence of other high risk criteria, and in the BTT setting, listing for simultaneous heart/kidney transplantation.

\section{Limitations}

A limitation of this analysis is the possibility of a type II error when there was a difference in outcomes between groups that simply was not detected because of sample size. Validation of these findings in larger cohorts is therefore important. In addition, renal dysfunction can be multifactorial and we did not distinguish etiology in our analysis. Finally, this is a single-institution series and the generalizability of these findings is unknown.

\section{CONCLUSIONS}

In this analysis of 238 patients who underwent LVAD implantation as BTT or DT, we found that preimplantation renal dysfunction was not a predictor of post-LVAD implantation survival or rates of transplantation. Furthermore, approximately one-half of patients with preoperative renal insufficiency recovered normal renal function by 1 year post-implantation. Therefore, these data suggest that renal dysfunction by itself should not serve as an absolute contraindication to LVAD therapy.

\section{Conflict of Interest Statement}

Authors have nothing to disclose with regard to commercial support.

\section{References}

1. Shah N, Agarwal V, Patel N, Deshmukh A, Chothani A, Garg J, et al. National trends in utilization, mortality, complications, and cost of care after left ventricular assist device implantation from 2005 to 2011. Ann Thorac Surg. 2016;101: 1477-84.

2. Kirklin JK, Naftel DC, Pagani FD, Kormos RL, Stevenson LW, Blume ED, et al. Seventh INTERMACS annual report: 15,000 patients and counting. J Heart Lung Transplant. 2015;34:1495-504

3. Kirklin JK, Naftel DC, Pagani FD, Kormos RL, Stevenson L, Miller M, et al. Long-term mechanical circulatory support (destination therapy): on track to compete with heart transplantation? J Thorac Cardiovasc Surg. 2012;144: 584-603.

4. Wilson SR, Mudge GH Jr, Stewart GC, Givertz MM. Evaluation for a ventricular assist device: selecting the appropriate candidate. Circulation. 2009;119: 2225-32.
5. Khot UN, Mishra M, Yamani MH, Smedira NG, Paganini E, Yeager M, et al. Severe renal dysfunction complicating cardiogenic shock is not a contraindication to mechanical support as a bridge to cardiac transplantation. J Am Coll Cardiol. 2003;41:381-5.

6. Kirklin JK, Naftel DC, Pagani FD, Kormos RL, Stevenson LW, Blume ED, et al. Sixth INTERMACS annual report: a 10,000-patient database. J Heart Lung Transplant. 2014;33:555-64.

7. Matthews JC, Koelling TM, Pagani FD, Aaronson KD. The right ventricular failure risk score a pre-operative tool for assessing the risk of right ventricular failure in left ventricular assist device candidates. J Am Coll Cardiol. 2008;51:2163-72.

8. Drakos SG, Janicki L, Horne BD, Kfoury AG, Reid BB, Clayson S, et al. Risk factors predictive of right ventricular failure after left ventricular assist device implantation. Am J Cardiol. 2010;105:1030-5.

9. Fitzpatrick JR III, Frederick JR, Hsu VM, Kozin ED, O'Hara ML, Howell E, et al. Risk score derived from pre-operative data analysis predicts the need for biventricular mechanical circulatory support. J Heart Lung Transplant. 2008;27: 1286-92.

10. Atluri P, Goldstone AB, Fairman AS, MacArthur JW, Shudo Y, Cohen JE, et al. Predicting right ventricular failure in the modern, continuous flow left ventricular assist device era. Ann Thorac Surg. 2013;96:857-63.

11. Klotz S, Vahlhaus C, Riehl C, Reitz C, Sindermann JR, Scheld HH. Pre-operative prediction of post-VAD implant mortality using easily accessible clinical parameters. J Heart Lung Transplant. 2010;29:45-52.

12. Lietz K, Long JW, Kfoury AG, MacArthur JW, Shudo Y, Cohen JE, et al. Outcomes of left ventricular assist device implantation as destination therapy in the post-REMATCH era: implications for patient selection. Circulation. 2007; 116:497-505.

13. Kim JH, Singh R, Pagani F, Desai SS, Haglund NA, Dunlay SM, et al. Ventricular assist device therapy in older patients with heart failure: characteristics and outcomes. J Card Fail. 2016;22:981-7.

14. Sandner SE, Zimpfer D, Zrunek P, Rajek A, Schima H, Dunkler D, et al. Renal function and outcome after continuous flow left ventricular assist device implantation. Ann Thorac Surg. 2009;87:1072-8.

15. Yoshioka D, Sakaguchi T, Saito S, Miyagawa S, Nishi H, Yoshikawa Y, et al. Predictor of early mortality for severe heart failure patients with left ventricular assist device implantation: significance of INTERMACS level and renal function. Circ J. 2012;76:1631-8.

16. Kirklin JK, Naftel DC, Kormos RL, Pagani FD, Myers SL, Stevenson LW, et al. Quantifying the effect of cardiorenal syndrome on mortality after left ventricular assist device implant. J Heart Lung Transplant. 2013;32: 1205-13.

17. Balsara KR, Keith A, Abou El Ela A, Joseph SM, Ewald GA, Silvestry SC, et al Pre-op renal failure is not associated with increased mortality following LVAD implantation. J Heart Lung Transplant. 2015;34:S224.

18. Singh M, Shullo M, Kormos RL, Lockard K, Zomak R, Simon MA, et al. Impact of renal function before mechanical circulatory support on posttransplant renal outcomes. Ann Thorac Surg. 2011;91:1348-54.

19. Hasin T, Topilsky Y, Schirger JA, Li Z, Zhao Y, Boilson BA, et al. Changes in renal function after implantation of continuous-flow left ventricular assist devices. J Am Coll Cardiol. 2012;59:26-36.

20. Deo SV, Sharma V, Altarabsheh SE, Hasin T, Dillon J, Shah IK, et al. Hepatic and renal function with successful long-term support on a continuous flow left ventricular assist device. Heart Lung Circ. 2014;23:229-33.

21. Jacobs S, Droogne W, Waelbers V, Bossche KV, Bollen H, Geens J, et al. Evolution of renal function after partial and full mechanical support for chronic heart failure. Int J Artif Organs. 2014;37:364-70.

22. Raichlin E, Baibhav B, Lowes BD, Zolty R, Lyden ER, Vongooru HR, et al. Outcomes in patients with severe preexisting renal dysfunction after continuous-flow left ventricular assist device implantation. ASAIO J. 2016;62:261-7.

Key Words: ventricular assist device, renal failure, outcomes, heart failure, morbidity 
TABLE E1. Number of patients at risk and $95 \%$ CIs for Figure 1

\begin{tabular}{|c|c|c|c|c|c|}
\hline Cohort & 0 mo & 1 mo & 3 mo & $6 \mathrm{mo}$ & $12 \mathrm{mo}$ \\
\hline \multicolumn{6}{|c|}{ BTT normal GFR } \\
\hline At risk & 48 & 39 & 26 & 15 & 10 \\
\hline $95 \% \mathrm{CI}$ & & $79-97$ & $75-95$ & $75-95$ & $75-95$ \\
\hline \multicolumn{6}{|c|}{ BTT reduced GFR } \\
\hline At risk & 47 & 40 & 28 & 21 & 10 \\
\hline $95 \% \mathrm{CI}$ & & $76-95$ & $68-91$ & $68-91$ & $53-88$ \\
\hline \multicolumn{6}{|c|}{ DT normal GFR } \\
\hline At risk & 54 & 50 & 43 & 31 & 25 \\
\hline $95 \% \mathrm{CI}$ & & $81-97$ & $75-94$ & $63-87$ & $60-85$ \\
\hline \multicolumn{6}{|c|}{ DT reduced GFR } \\
\hline At risk & 84 & 77 & 67 & 47 & 34 \\
\hline $95 \% \mathrm{CI}$ & & $85-97$ & $80-94$ & $62-82$ & $50-73$ \\
\hline
\end{tabular}

$B T T$, Bridge to transplantation; GFR, glomerular filtration rate; $C I$, confidence interval; $D T$, destination therapy.

TABLE E2. Number of patients at risk and $95 \%$ CIs for Figure 2

\begin{tabular}{|c|c|c|c|c|}
\hline Cohort & 0 mo & 3 mo & $6 \mathrm{mo}$ & $12 \mathrm{mo}$ \\
\hline \multicolumn{5}{|c|}{ BTT normal GFR } \\
\hline At Risk & 49 & 26 & 12 & 5 \\
\hline $95 \% \mathrm{CI}$ & & $84-103$ & $77-104$ & $50-116$ \\
\hline \multicolumn{5}{|c|}{ BTT reduced GFR } \\
\hline At Risk & 47 & 21 & 13 & 7 \\
\hline $95 \% \mathrm{CI}$ & & $61-79$ & $58-81$ & $49-87$ \\
\hline \multicolumn{5}{|c|}{ DT normal GFR } \\
\hline At Risk & 54 & 41 & 26 & 20 \\
\hline $95 \% \mathrm{CI}$ & & $74-90$ & $74-95$ & $75-97$ \\
\hline \multicolumn{5}{|c|}{ DT reduced GFR } \\
\hline At Risk & 85 & 52 & 33 & 24 \\
\hline $95 \% \mathrm{CI}$ & & $55-67$ & $50-63$ & $48-66$ \\
\hline
\end{tabular}

$B T T$, Bridge to transplantation; GFR, glomerular filtration rate; $C I$, confidence interval; $D T$, destination therapy. 